\title{
OPTIMASI SISTEM PENEMPATAN MAGANG MENERAPKAN ALGORITME GENETIKA
}

\author{
Satrio Agung Wicaksono ${ }^{1}$ \\ Fakultas Ilmu Komputer Universitas Brawijaya ${ }^{1}$ \\ Email: ${ }^{1}$ satrio@ub.ac.id
}

(Naskah masuk: 23 Juli 2018, diterima untuk diterbitkan: 20 Desember 2018)

\begin{abstract}
Abstrak
Magang merupakan proses yang penting dalam proses belajar mengajar di SMK. Secara spesifik magang di SMK disebut Prakerin (Praktek Kerja Industri). Penempatan magang harus memerhatikan kompetensi siswa, kuota dari perusahaan, kesesuaian jurusan dengan lowongan, dan penghasilan orang tua. Penempatan magang secara manual selama ini memakan waktu, sehingga kurang efisien. Oleh karena itu, penelitian ini fokus mengembangkan aplikasi dengan menerapkan pendekatan Algoritme Genetika untuk mempermudah dalam menentukan penempatan magang dengan menerapkan aturan yang berlaku. Algoritme Genetika dinilai sebagai algoritma yang relevan dan solutif untuk diterapkan dalam penyelesaian masalah optimasi kompleks. Masalah yang dimaksud umumnya adalah masalah yang sulit dilakukan dengan menerapkan metode konvensional. Algoritme Genetika memberikan hasil yang lebih baik untuk setiap iterasi pencarian solusi. Hasil fitness terbaik dengan nilai 0.0014286 diperoleh pada jumlah individu 200, jumlah generasi 200, persentase crossover $50 \%$ dan mutasi $10 \%$. Hasil validasi dengan pihak SMK menyatakan bahwa sistem ini mudah untuk digunakan dan bermanfaat bagi pihak SMK, dengan rata-rata persentase kualitas sistem 82,5\%. Algoritme Genetika efektif untuk diterapkan pada studi kasus penjadwalan atau penempatan magang yang memiliki karakteristik data yang kompleks.
\end{abstract}

Kata kunci: Algoritme Genetika, optimasi, penempatan Prakerin, 77

\begin{abstract}
Internships are an important component of teaching and learning activities in vocational high schools (SMK). Specifically the internship in SMK is called Prakerin (Industrial Work Practice). The internship placement should considering student competence, number of vacancies, the suitability of majors with vacancy, and the income of the parent. During this time, manual internship placement takes more time, so less efficient. Therefore, this research tries to approach using Genetic Algorithm to make it easier in determining the internship placement by applying the applicable rules. The Genetic Algorithm is judged as the right algorithm used in solving complex optimization problems, which is difficult to do by conventional methods. The Genetic Algorithm provides better results for each iteration of the solution search. Best fitness results with value 0.0014286 obtained on the number of individuals 200, the number of generation 200, the percentage of crossover 50\% and the mutation $10 \%$. Validation results with the SMK stated that the system is easy to use and beneficial to the SMK, with an average percentage of system quality about $82.5 \%$. Genetic Algorithms are effective to apply to scheduling case studies or internship placements that have complex data characteristics.
\end{abstract}

Keywords: Genetic Algorithm, optimization, internship placement, Vocational High School students

\section{PENDAHULUAN}

Pendidikan Sistem Ganda atau PSG membutuhkan peran dan kerja sama dengan pihak industri agar terbentuk pembelajaran dengan model industry-based system. Prakerin adalah bagian dari Pendidikan Sistem Ganda (PSG) sebagai program bersama antara SMK dan industri yang dilaksanakan di dunia usaha dan dunia industri (Ningsih, Lusiani, \& Nurcahyawati, 2012). Dalam kurikulum SMK disebutkan : "Prakerin adalah pola penyelenggara diklat yang dikelola bersama-sama antara SMK dengan industri/asosiasi profesi sebagai institusi pasangan (IP), mulai dari tahap perencanaan, pelaksanaan hingga evaluasi dan sertifikasi yang merupakan satu kesatuan program dengan menggunakan berbagai bentuk alternatif pelaksanaan, seperti day release, block release, dan sebagainya". Tujuan dari pembelajaran dengan model industry-based system adalah memberikan kesempatan siswa SMK untuk mempraktekkan keterampilannya di dunia kerja (Irianti, Marji, Suhartadi, \& Widowati, 2016).

Pada proses pelaksanaan Prakerin siswa SMK mengalami berbagai kendala dari proses memilih hingga proses diterima di tempat magang. Penempatan prakerin dinilai tidak selalu sesuai dengan kompetensi siswa (Rokhmawati \& Wicaksono, 2017). Umumnya, proses yang ditempuh siswa yang akan Prakerin antara lain siswa 
harus mengajukan proposal ke perusahaan tempat prakerin, atau SMK menempatkan siswa SMK berdasarkan kerjasama dengan perusahaan. Penempatan didasarkan dari berbagai pertimbangan misalnya kompetensi siswa, daya tampung industri, fasilitas bagi siswa magang, dan kemampuan finansial orang tua. Proses ini dilakukan dalam waktu yang cukup panjang karena harus melakukan sosialisasi terlebih dahulu ke orang tua siswa. Di sisi lain, siswa yang dinyatakan gagal masuk Prakerin ke sebuah industri juga perlu dicarikan alternatif tempat Prakerin lainnya. Guna mengatasi masalah tersebut, penempatan Prakerin membutuhkan rekomendasi yang cepat dan tepat, sehingga siswa mendapatkan tempat Prakerin yang sesuai dengan kemampuan dan kebutuhannya. Penentuan tempat Prakerin yang sesuai dengan keminatan siswa juga memengaruhi minat siswa dalam berwirausaha (Arisandi \& Suparji, 2013), sehingga lulusan SMK pun mampu menciptakan lapangan pekerjaan berdasarkan pengalaman yang diperoleh sebelumnya.

Penelitian ini fokus pada Jurusan TKJ (Teknik Komputer dan Jaringan) dan Jurusan RPL (Rekayasa Perangkat Lunak) yang memerhatikan beberapa aspek dalam menempatkan siswa yang akan Prakerin. Kedua jurusan ini dipilih aspek pertimbangan penempatan Prakerin yang sama. Aspek tersebut antara lain: kompetensi yang dibutuhkan industri, kompetensi siswa (Rokhmawati \& Wicaksono, 2017), daya tampung/jumlah lowongan, fasilitas yang disediakan industri, dan gaji orang tua siswa.

Penelitian terdahulu lebih banyak membahas penerapan algoritma untuk optimasi pemilihan rute. Proses pencarian solusi permasalahan ini adalah dengan mengombinasikan solusi-solusi (kromosom), sehingga dapat menghasilkan solusi baru dengan menggunakan operator genetika (seleksi, crossover dan mutasi) (Suprayogi \& Mahmudy, 2015). Selanjutnya, penerapan algoritma genetika kerap digabungkan dengan metode Travelling Salesman Problem (TSP) untuk menentukan rute perjalanan dalam sistem rekomendasi pariwisata (Hendra, L, \& Baizal, 2018). Tidak banyak referensi penelitian tentang penerapan algoritma genetika dalam menentukan penempatan di bidang sosial, khususnya pendidikan. Kesulitan pada penelitian ini adalah proses akuisisi data. Mayoritas SMK belum menyimpan dan mengelola data penempatan magang secara sistematis dan data umumnya berupa data kualitatif. Perbedaan mendasar pada penelitian ini adalah penggunaan metode pengujian User Acceptance Testing (UAT). SMK selaku stakeholder membutuhkan proses uji coba sistem rekomendasi ini yang dikaitkan dengan konteks kasus yang terjadi di SMK. Salah satu tujuan UAT adalah untuk mengukur kepuasan target pengguna terhadap sistem yang diujicobakan (Hambling \& Goethem, 2013) dan sebagai bentuk pengujian perangkat lunak untuk memastikan sistem dapat diterima pengguna dari sudut pandang Quality Assurance (Jayaraman \& Sumithra Sundaresan, 2018).

Berdasarkan masalah yang dipaparkan, penelitian ini bertujuan untuk membantu pembuatan rekomendasi penempatan Prakerin siswa SMK, sehingga keputusan yang diambil memiliki relevansi yang tinggi dengan aspek yang dipertimbangkan. Dalam penelitian ini diusulkan penerapan Algoritme Genetika yang merupakan algoritma pencarian heuristik yang didasari mekanisme seleksi alami dan genetika alami. Algoritme Genetika merupakan salah satu algoritma yang sangat tepat untuk diterapkan dalam penyelesaian masalah optimasi yang kompleks, dimana masalah ini sulit diselesaikan oleh metode konvensional (Muliadi, 2014). Algoritme Genetika bersifat mencari kemungkinan dari calon solusi hingga mendapatkan solusi yang optimal.

\section{DASAR TEORI}

\subsection{Algoritme Genetika}

Algoritme Genetika merupakan algoritma pencarian heuristik yang didasari mekanisme seleksi alami dan genetika alami. Pertama kali, Algoritme Genetika dikembangkan oleh John Holland pada tahun 1975. Beberapa istilah pada Algoritme Genetika misalnya, kromosom dan mutasi berasal dari genetika populasi (Higuchi, Liu, Iwata, \& Yao, 2006).

Algoritme Genetika menjadi salah satu algoritma yang solutif dan sering digunakan dalam menyelesaikan masalah optimasi kompleks. Masalah yang dimaksud adalah masalah yang sulit diselesaikan oleh metode konvensional. Algoritme Genetika menerapkan proses heuristik, sehingga membutuhkan metode lain untuk menciptakan proses heuristik pada Algoritme Genetika. Tujuannya agar Algoritme Genetika menjadi terarah dan membuat keseluruhan proses menjadi lebih efisien (Kramer, 2017). Pencarian yang dilakukan oleh Algoritme Genetika melibatkan dua tahap yaitu tahap persiapan dan tahap pencarian.

\subsection{Kromosom}

Tahapan awal Algoritme Genetika adalah mengonversi masalah riil menjadi terminologi biologi dalam bentuk kromosom. Kromosom ini nantinya sebagai salah satu solusi yang mungkin. Kromosom merupakan kumpulan gen (Kramer, 2017). Pada penelitian ini, pembentukan kromosom dibuat dengan melakukan pengokodean nilai. Pengkodean nilai diterapkan pada masalah yang sangat kompleks. Nilai yang dikodekan harus merepresentasikan masalah riil. Penerapan kode biner pada jenis masalah yang kompleks akan menjadi lebih sulit.

Tahap pengkodean nilai menghasilkan kromosom yang pada setiap kromosom adalah 
barisan dari beberapa nilai. Nilai yang dimaksud dapat berupa bilangan biasa, bilangan riil, karakter bahkan berupa obyek-obyek yang rumit.

Tabel 1 Contoh kromosom pada pengkodean nilai.

\begin{tabular}{ll}
\hline Kromosom A & [red], [black], [blue], [yellow], [red] \\
\hline Kromosom B & $1,4,5,10,11,2,6,7,9$ \\
\hline Kromosom C & A, B, C, D, E, F, G, H, I, J, K, L, M, N \\
\hline
\end{tabular}

\subsection{Nilai Fitness}

Terdapat tiga aspek yang penting dalam penerapan Algoritme Genetika, antara lain pendefinisian fitness, pendefinisian dan implementasi representasi genetik, serta pendefinisian dan implementasi operasi genetik. Apabila ketiga aspek tersebut terdefinisi, maka Algoritme Genetika akan bekerja dengan baik.

Penerapan Algoritme Genetika diawali dengan populasi yang berisi kumpulan solusi. Kumpulan solusi yang diambil dari sebuah populasi selanjutnya digunakan untuk membentuk populasi yang baru. Hal ini bertujuan agar populasi yang baru dibentuk dapat menghasilkan solusi yang lebih baik daripada kumpulan solusi dari populasi yang lama. Kriteria pemilihan solusi untuk membentuk solusi-solusi yang baru dipilih berdasarkan nilai fitness mereka masing-masing.

Secara umum, Algortima Genetika dapat dijelaskan sebagai berikut (Mutakhiroh, Saptono, Hasanah, \& Wiryadinata, 2007):

a. Pada tahap populasi awal terjadi proses pembangkitan populasi awal secara random sehingga didapatkan solusi awal.

b. Setiap populasi yang telah didapatkan kemudian dievaluasi fitness-nya dengan menghitung nilai fitness setiap kromosom. Proses evaluasi dilakukan sampai kriteria untuk berhenti terpenuhi.

c. Setelah proses evaluasi, berlanjut ke proses seleksi yang bertujuan untuk memberikan kesempatan reproduksi yang lebih besar. Reproduksi yang lebih besar difokuskan untuk anggota populasi yang paling baik. Melalui seleksi akan didapatkan individuindividu mana saja yang akan dipilih untuk mendapatkan generasi baru.

d. Proses perkawinan silang (crossover) merupakan proses pertukaran dua kromosom sehingga menciptakan populasi baru. Populasi baru ini yang akan mewarisi karakter dari populasi lama. Melalui perkawinan silang, dapat dihasilkan keanekaragaman string dalam satu populasi.

e. Selanjutnya, proses mutasi dilakukan mengubah nilai dari satu atau beberapa gen dalam suatu kromosom. Proses ini berperan untuk menggantikan gen yang hilang dari populasi. Umumnya gen hilang akibat proses seleksi yang memungkinkan munculnya kembali gen yang semula tidak muncul pada inisialisasi populasi.

f. Kriteria berhenti adalah kriteria yang dijadikan acuan untuk menghentikan proses Algoritme Genetika.

g. Hasil adalah solusi optimum yang didapat dari penerapan Algoritme Genetika.

\subsection{User Acceptance Testing}

UAT atau User Acceptance Testing adalah pengujian yang umumnya digunakan untuk menguji perangkat lunak dari sisi pengguna akhir yang dilakukan sebelum sistem informasi baru diimplementasikan ke suatu organisasi. Tujuan utama dari UAT adalah untuk memastikan sistem baru beroperasi sesuai dengan yang direncanakan dan memenuhi persyaratan dari aktivitas yang ditentukan (Hambling \& Goethem, 2013).

UAT adalah proses verifikasi suatu solusi/sistem yang berfungsi untuk memenuhi kebutuhan pengguna. UAT bukan bertujuan memastikan perangkat lunak tidak memiliki kesalahan dan memenuhi persyaratan tetapi memastikan bahwa solusi akan bekerja untuk pengguna (Sualim, Yassin, \& Mohamad, 2016). Pada pengujian dengan UAT terdapat beberapa tipe pengujian yang dapat dilakukan. Pada penelitian ini tipe pengujian yang paling sesuai adalah tipe functional testing.

Pada Gambar 1 dapat dilihat bahwa test case functional telah dibuat dengan mempertimbangkan kondisi pengujian. Data-data yang akan dimasukkan perlu ditentukan di dalam test case, kemudian diterapkan pada fungsi yang akan diuji. Pengujian dengan tipe functional testing di dalam UAT diharapkan sebagian besar test case menunjukkan bahwa sistem telah berfungsi dengan baik dan dapat diterima oleh pengguna akhir (Hambling \& Goethem, 2013).

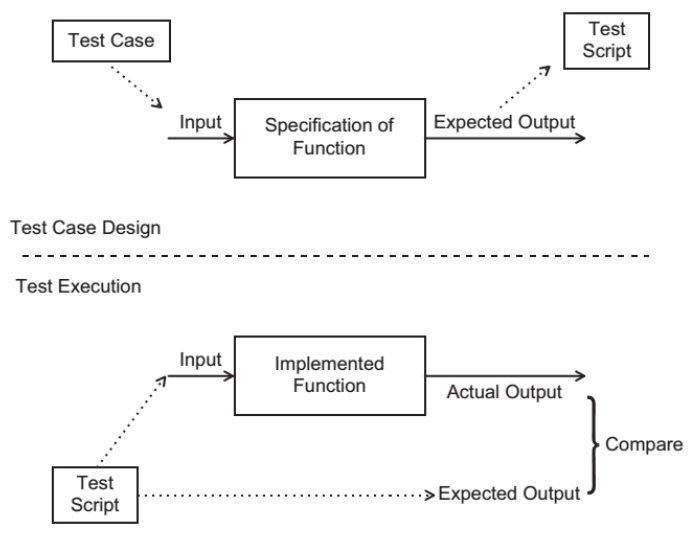

Gambar 1. Functional Testing pada UAT

\section{METODE PENELITIAN}

Pada Gambar 2 ditunjukkan alur metode penelitian yang dilakukan. 


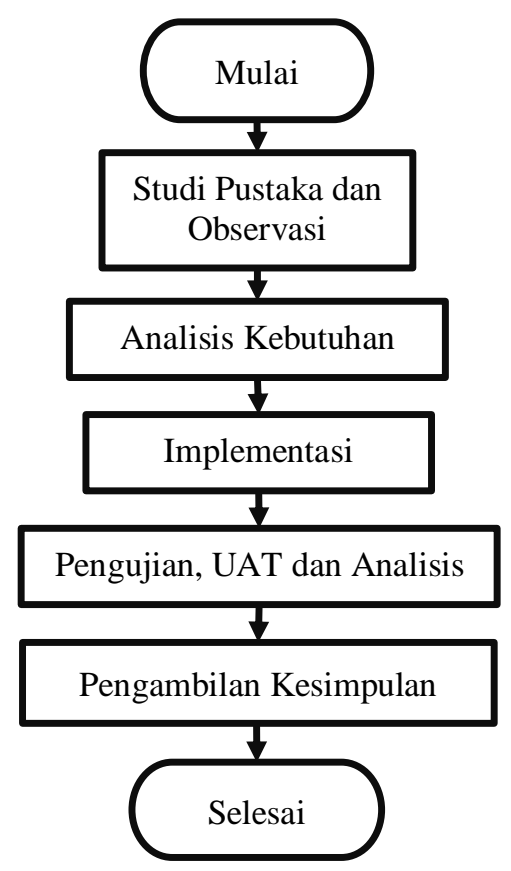

Gambar 2. Alur Metode Penelitian

Penelitian diawali dengan observasi proses bisnis saat ini di SMK Negeri di Malang. Hasil observasi dikaji dengan konsep Pendidikan Sistem Ganda dan mekanisme magang. Masing-masing SMK Negeri memiliki pertimbangan yang berbeda dalam menempatkan siswa magang, sehingga dipilih jurusan RPL dan TKJ yang memiliki kriteria yang sama. Hasil analisis kebutuhan ditemukan faktorfaktor yang dipertimbangkan dalam penempatan magang, antara lain kompetensi siswa tang ditunjukkan dari nilai ujian, daya tampung industri yang ditunjukkan dari jumlah lowongan, fasilitas dari tempat magang berupa uang saku atau tempat tinggal, gaji yang diberikan oleh tempat magang, dan kemampuan finansial orang tua.

Setelah hasil analisis kebutuhan didapat, penelitian fokus pada menentukan constraint untuk mendukung implementasi Algoritme Genetika (AG). Algoritme Genetika memiliki sifat mencari kemungkinan dari calon solusi. Tujuannya untuk mendapatkan solusi yang optimum dalam penyelesaian masalah. Cakupan dari semua solusi yang layak dari berbagai obyek disebut ruang pencarian.

Sistem penempatan Prakerin yang telah menerapkan Algoritme Genetika selanjutnya akan diuji atau divalidasi. Validasi yang dilakukan bertujuan untuk memastikan rekomendasi yang dikeluarkan valid dan sistem dapat digunakan secara fungsional. Pengujian juga dilakukan dari sisi pengguna langsung sistem. Kriteria peserta User Acceptance Testing adalah guru yang mengelola magang SMK di Jurusan RPL (Guru A) dan TKJ (Guru B), masing-masing jurusan memiliki kriteria penempatan magang yang sama, dan guru memiliki latar belakang pendidikan TI.

\section{HASIL DAN PEMBAHASAN}

Berdasarkan hasil observasi dengan pihak SMK, terdapat banyak parameter yang perlu diperhatikan antara lain, kompetensi yang dibutuhkan industri, kompetensi siswa SMK yang ditunjukkan dengan nilai ujian kompetensi, daya tampung industri, fasilitas yang disediakan industri untuk siswa magang, reward berupa gaji untuk siswa SMK, gaji orang tua, dan jarak antara tempat tinggal dengan tempat magang. Kendala utama dari penelitian ini adalah sulitnya mendapatkan data lengkap tentang semua parameter tersebut, sehingga penelitian ini fokus pada parameter yang datanya tersedia dan cukup layak untuk dinalaisis. Penelitian ini menggunakan parameter kesesuaian jurusan dengan lowongan magang, kuota lowongan magang, nilai ujian kompetensi siswa, dan gaji orang tua. Beberapa hal yang perlu diperhatikan dalam penerapan Algoritme Genetika antara lain jumlah individu yang digunakan, generasi, dan persentase perkawinan silang, dan mutasi yang digunakan. Dalam penelitian ini, akan dicari beberapa nilai parameter yang mengoptimalkan proses penempatan magang.

\subsection{Representasi Kromosom}

Pemberntukan koromosom merupakan proses awal dari algoritma genetika. Pada penelitian ini menggunakan representasi kromosom dalam bentuk pengkodean nilai seperti ditunjukkan pada tabel 2 .

Tabel 2. Representasi Kromosom

\begin{tabular}{crrrrrr}
\hline INDUSTRI & \multicolumn{3}{c}{ PERUSAHAAN 1 } & \multicolumn{3}{c}{ PERUSAHAAN 2 } \\
\hline POSISI & P1 & P2 & P3 & P1 & P2 & P3 \\
\hline Kromosom 1 & 1 & 5 & 2 & 6 & 8 & 1 \\
\hline Kromosom 2 & 9 & 3 & 5 & 6 & 10 & 1 \\
\hline
\end{tabular}

Setiap gen pada kromosom di tabel 2 mewakili data siswa yang terdiri dari NIS, NAMA, JURUSAN, NILAI UJI KOMPETENSI, GAJI ORANG TUA dan MINAT TEMPAT MAGANG. Selain mewakili data siswa setiap gen juga memilihi header yang terdiri dari nama perusahan (PERUSAHAAN 1) dan posisi penempatan (P1, P1 merupakan kode dari posisi siswa yang nantinya akan ditempatkan, contoh : P1: Programmer Web) . Setiap gen pada tabel 2 akan dihitung nilai pinalti berdasarkan aturan pada tabel 3 .

Tabel 3. Aturan dan Nilai Pinalti

\begin{tabular}{lc}
\hline Konstrain & Pinalti \\
\hline Ketidak sesuaian jurusan & 7 \\
$\begin{array}{l}\text { Ketidak sesuaian tempat } \\
\text { magang }\end{array}$ & 1 \\
\hline & 5 \\
$\begin{array}{l}\text { Tidak memenuhi syarat } \\
\text { minimal nilai uji kompentensi }\end{array}$ & \\
\hline
\end{tabular}




\begin{tabular}{lc}
\hline Konstrain & Pinalti \\
\hline Minimum gaji orang tua & 1 \\
\hline & 2 \\
Maksimum gaji orang tua & \\
\hline
\end{tabular}

4.2 Pengaruh jumlah generasi pada proses Algoritme Genetika

Proses ini dilakukan dengan tujuan untuk mendapatkan nilai jumlah generasi terbaik dalam proses genetik yaitu dengan mencari pada generasi ke berapa nilai fitness mencapai titik konvergen. Hasil percobaan dengan menggunakan 100 individu dan $50 \%$ crossover dengan berbagai variasi jumlah dapat dilihat pada Gambar 3.

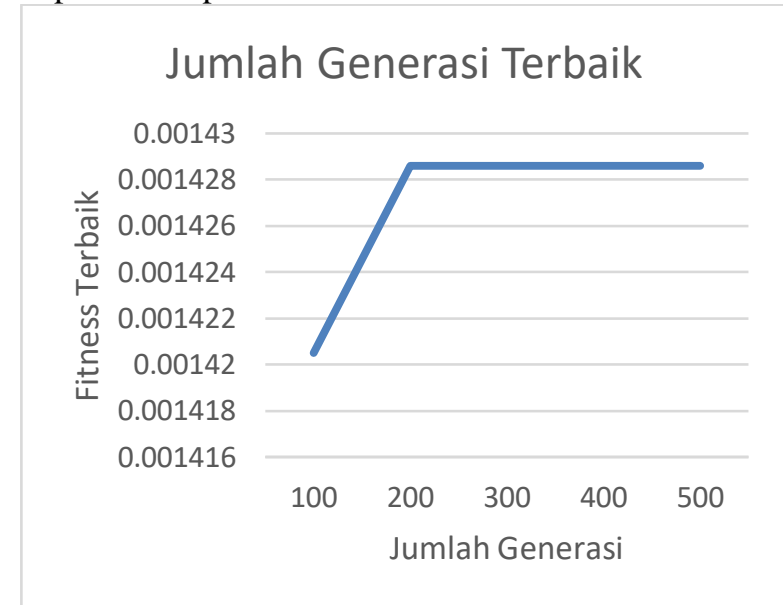

Gambar 3. Generasi untuk titik konvergensi

Berdasarkan Gambar 3, dapat dilihat bahwa pada generasi ke 200 nilai fitness sudah mengalami konvergensi sehingga pada pengujian selanjutnya akan menggunakan jumlah generasi sebanyak 200.

\subsection{Pengaruh jumlah individu pada proses} Algoritme Genetika

Setelah diperoleh jumlah generasi terbaik, selanjutnya dilakukan uji coba terhadap berbagai variasi jumlah individu karena jumlah individu dalam satu populasi memiliki pengaruh terhadap nilai fitness. Pengujian jumlah individu dilakukan dengan melakukan perubahan jumlah individu dengan nilai 50, 75, 100, 200 dan 300, probabilitas crossover $50 \%$ dan probabilitas mutasi $10 \%$. Hasil percobaan dapat dilihat pada Gambar 4.

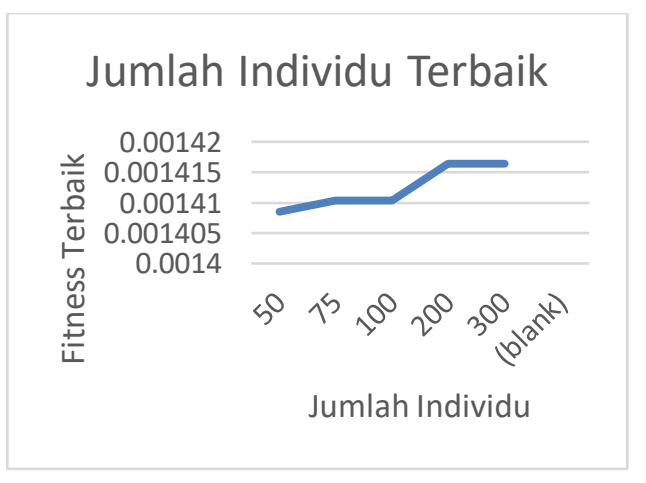

Gambar 4. Fitness Terbaik Dipengaruhi Jumlah Individu

Jumlah individu memiliki pengaruh terhadap nilai fitness terbaik hal tersebut dapat dilihat pada Gambar 4. Dari Gambar 4 menunjukkan semakin banyak individu pada populasi akan menghasilkan nilai fitness yang lebih baik daripada jumlah individu yang lebih sedikit pada sebuah populasi. Namun pada jumlah indvidu tertentu sudah terjadi konvergen terhadap nilai fitness. Pada Gambar 4, jumlah individu terbaik adalah 200, karena setelah jumlah individu sebanyak 200, nilai fitness terbaik sudah mengalami konvergensi.

4.4 Pengaruh probabilitas crossover pada proses Algoritme Genetika

Dari hasil percobaan sebelumnya sudah diperoleh jumlah generasi terbaik dan jumlah individu terbaik dalam satu populasi. Selanjutnya dilakukan uji coba untuk mengetahui pengaruh probabilitas crossover terhadap nilai fitness pada Algoritme Genetika. Untuk memperoleh nilai probabilitas crossover terbaik dilakukan dengan mencoba berbagai variasi probabilitas crossover mulai dari $25 \%, \quad 50 \%, \quad 75 \%$ dan $80 \%$ dan probabilitas mutasi $10 \%$. Hasil percobaan terhadap perubahan nilai probabilitas crossover ditujukkan pada Gambar 5.

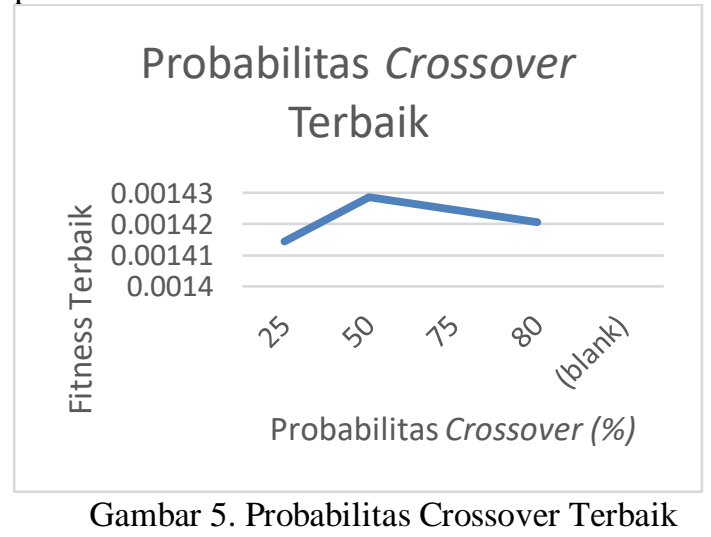

Pada Gambar 5 menunjukkan probabilitas crossover terbaik pada nilai 50\%. Dari hasil pengujian perubahan crossover menunjukkan bahwa semakin besar probabilitas crossover tidak memberikan jaminan bahwa nilai fitness yang dihasilkan akan lebih baik dari probabilitas crossover yang lebih kecil.

\subsection{Hasil User Acceptance Testing dengan Guru SMK}

Penempatan magang menggunakan Algoritme Genetika sehingga dapat diperoleh solusi berupa struktur kromosom serta parameter operator genetika terbaik, sistem cerdas ini juga diharapkan dapat memberikan solusi yang bisa langsung berdampak terhadap penempatan magang pada SMK. Sehingga untuk mengetahui kebermanfaat dari sistem cerdas ini maka perlu dilakukan pengujian validasi dengan SMK. Sistem Cerdas Penempatan Magang ini telah 
diujicobakan kepada perwakilan guru SMKN di Malang yang menangani penempatan magang di SMK masing-masing. Sebanyak 2 guru terlibat dalam uji coba ini. Berikut pada Tabel 4 adalah hasil umpan balik yang disampaikan oleh 2 guru SMKN di Malang. Hasil uji coba terdapat pada Tabel 4.

Tabel 4. Hasil User Acceptance Testing dengan Guru SMKN di Malang

\begin{tabular}{|c|c|c|}
\hline $\begin{array}{l}\text { Aspek } \\
\text { Pengujian }\end{array}$ & Guru A & Guru B \\
\hline $\begin{array}{l}\text { Kemudahan } \\
\text { sistem }\end{array}$ & $\begin{array}{l}\text { Sangat Mudah } \\
\text { (skala } 5 \text { dari } 5 \text { ) }\end{array}$ & $\begin{array}{l}\text { Mudah (skala } 4 \\
\text { dari } 5 \text { ) }\end{array}$ \\
\hline $\begin{array}{l}\text { Kemudahan } \\
\text { penjelasan }\end{array}$ & $\begin{array}{l}\text { Mudah (skala } 4 \text { dari } \\
5 \text { ) }\end{array}$ & $\begin{array}{l}\text { Mudah (skala } 4 \\
\text { dari } 5 \text { ) }\end{array}$ \\
\hline $\begin{array}{l}\text { Substansi } \\
\text { konten }\end{array}$ & $\begin{array}{l}\text { Memuaskan (skala } 4 \\
\text { dari } 5 \text { ) }\end{array}$ & $\begin{array}{l}\text { Memuaskan } \\
\text { (skala } 4 \text { dari 5) }\end{array}$ \\
\hline $\begin{array}{l}\text { Manfaat sistem } \\
\text { bagi SMK }\end{array}$ & $\begin{array}{l}\text { Cukup bermanfaat } \\
\text { (skala } 3 \text { dari } 5 \text { ) }\end{array}$ & $\begin{array}{l}\text { Bermanfaat (skala } \\
4 \text { dari 5) }\end{array}$ \\
\hline $\begin{array}{l}\text { Kualitas sistem } \\
(\%)\end{array}$ & $85 \%$ & $80 \%$ \\
\hline Saran & $\begin{array}{l}\text { Sudah bagus, } \\
\text { mungkin ke depan } \\
\text { lebih disesuaikan } \\
\text { dengan } \\
\text { perkembangan di } \\
\text { SMK, seperti jarak } \\
\text { tempuh dari rumah } \\
\text { ke tempat DU/DI. }\end{array}$ & $\begin{array}{l}\text { Variabel perlu } \\
\text { disesuaikan } \\
\text { dengan kebutuhan } \\
\text { masing-masing } \\
\text { jurusan. } \\
\text { Kedepannya perlu } \\
\text { ditambahkan fitur } \\
\text { penugasan untuk } \\
\text { siswa yang } \\
\text { Prakerin. }\end{array}$ \\
\hline
\end{tabular}

Pengujian validasi dilakukan terhadap 6 aspek yaitu kemudahan sistem, kemudahan penjelasan, substansi konten, manfaat sistem bagi SMK, presentase kualitas sistem dan saran. Pada Tabel 4 dapat dilihat bahwa dari semua aspek pengujian validasi menunjukkan bahwa sistem cerdas penempatan magang dapat diterima oleh pengguna langsung dalam hal ini adalah SMK.

\section{KESIMPULAN}

Optimasi sistem penempatan magang menerapkan Algoritme Genetika mampu membantu dalam menyelesaikan masalah penempatan magang siswa smk. Dari hasil penelitian dapat ditarik kesimpulan sebagai berikut :

1. Constraint yang memengaruhi dalam penempatan Prakerin SMKN di Malang adalah

a. Kesesuaian jurusan dengan lowongan.

b. Kesesuaian minat penempatan magang.

c. Batas minimal nilai uji kompetensi.

d. Batas atas/bawah penghasilan orang tua. Data Prakerin SMKN di Malang tidak ditemukan penentuan klasifikasi penghasilan orang tua, namun faktor ini secara kualitatif memengaruhi penentuan penempatan Prakerin.

2. Pada penelitian ini kromosom dibuat dengan menggunakan pengkodean integer.
3. Hasil fitness terbaik dengan nilai 0.0014286 diperoleh pada jumlah individu 200, jumlah generasi 200, persentase crossover $50 \%$ dan mutasi $10 \%$.

4. Hasil validasi dengan pihak SMK menyatakan bahwa sistem ini mudah untuk digunakan dan bermanfaat bagi pihak SMKN di Malang, dengan rata-rata persentase kualitas sistem $82,5 \%$.

Penelitian selanjutnya dapat dikembangkan dengan menggunakan constraint yang bisa ditentukan secara dinamis karena berbeda jurusan SMK dapat memiliki constraint yang berbeda.

\section{DAFTAR PUSTAKA}

ARISANDI, A., \& SUPARJI. (2013). Pengaruh Praktik Kerja Industri ( Prakerin ) Terhadap Kompetensi Siswa SMKN 1 Sidoarjo. Jurnal Kajian Pendidikan Teknik Bangunan, 1(3), 1$9 . \quad$ Diambil dari http://id.portalgaruda.org/?ref=browse \&mod= viewarticle\&article $=102683$

HAMBLING, B., \& GOETHEM, P. VAN. (2013). User Acceptance Testing: A Step-by-Step Guide. Journal of Chemical Information and Modeling (Vol. 53).

HENDRA, F., L, K. M., \& BAIZAL, Z. K. A. (2018). Penerapan Algoritme Genetika untuk Menentukan Rute Perjalanan Dalam Sistem Rekomendasi Pariwisata Application of Genetic Algorithm for Determining Travel Route in Tourism Recommendation System. $e$ Proceeding of Engineering, 5(1), 1632-1638.

HIGUCHI, T., LIU, Y., IWATA, M., \& YAO, X. (2006). Introduction to Evolvable Hardware. In IEEE Computational Intelligence Magazine (Vol. 1, hal. 1-19). New York: Springer. http://doi.org/10.1109/MCI.2006.1597058

IRIANTI, A. H. S., MARJI, SUHARTADI, S., \& WIDOWATI, T. (2016). Analisis Pelaksanaan Prakerin Siswa SMK Program Keahlian Tata Busana di Malang Raya. Jurnal Teknologi dan Kejuruan, 39(1), 33-44.

JAYARAMAN, V. S., \& SUMITHRA SUNDARESAN. (2018). ( 12 ) Patent Application Publication ( 10 ) Pub . No . : US 2018 / 0095859 A1.

KRAMER, O. (2017). Genetic Algorithm Essentials (Vol. 534). Switzerland: Springer International Publishing. http://doi.org/10.1007/978-3-31952156-5

MULIADI. (2014). Pemodelan Algoritme Genetika pada Sistem Penjadwalan Perkuliahan Prodi Ilmu Komputer Universitas Lambungmangkurat. Kumpulan Jurnal Ilmu Komputer (KLIK), 01(01), 67-78.

MUTAKHIROH, I., SAPTONO, F., HASANAH, 
N., \& WIRYADINATA, R. (2007). Pemanfaatan Metode Heuristik Dalam Pencarian Jalur Terpendek Dengan Algoritme Semut dan Algoritme Genetika. SNATI (Seminar Nasional Aplikasi Teknologi Informasi) 2007, 2007(Snati), B33-B39. Diambil dari http://journal.uii.ac.id/index.php/Snati/article/v iewFile/1623/1398

NINGSIH, P. W., LUSIANI, T., \& NURCAHYAWATI, V. (2012). Rancang Bangun Sistem Informasi Praktek Kerja Industri Berbasis Web. Jurnal Sistem Informasi Komputer Akuntansi, 1(1).

ROKHMAWATI, R. I., \& WICAKSONO, S. A. (2017). An analysis of determinants and obstacles of vocational high school students ' internships. In Abdullah (Ed.), Regionalization and Harmonization in TVET (hal. 23-26). Taylor \& Francis Group, London.

SUALIM, S. A., YASSIN, N. M., \& MOHAMAD, R. (2016). Comparative Evaluation of Automated User Acceptance Testing Tool for Web Based Application, 02(2), 1-6.

SUPRAYOGI, D. A., \& MAHMUDY, W. F. (2015). Penerapan Algoritme Genetika Traveling Salesman Problem with Time Window: Studi Kasus Rute Antar Jemput Laundry. Jurnal Buana Informatika, 6(2), 121-130. 
Halaman ini sengaja di kosongkan 